\title{
Mittel und Medien
}

TIGER FÜR DIE MIKROWELLE

\section{Warm und kuschelig}

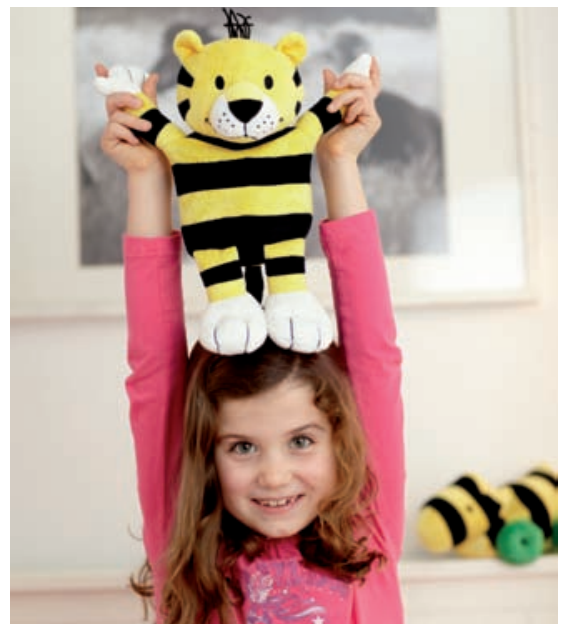

- Janoschs Geschichten vom kleinen Tiger haben einen festen Platz in den Herzen vieler Kinder eingenommen. Nun gibt es den Tiger und die Tigerente als Wärmestofftiere: Die Warmies sind Spielkameraden oder Trostspender. Mit ihrer Lavendel-Hirse-Füllung lassen sie sich schnell erwärmen und spenden lang anhaltend Wärme. Seit 2005 vertreibt Greenlife Value Wärme-Produkte für die ganze Familie. Neben Tiger und Tigerente bietet es weitere Wärmestofftiere an. Außerdem Slipper, Nackenwärmer oder Wärmflaschen. Die Warmies sind im Fachhandel, in Apotheken und auf der Website der Firma erhältlich. Tiger und Tigerente kosten jeweils 24,99 Euro. Nach Angaben von Greenlife Value

$\Rightarrow$ www.warmies.de

@

ZU GEWINNEN

\section{Einen Tiger}

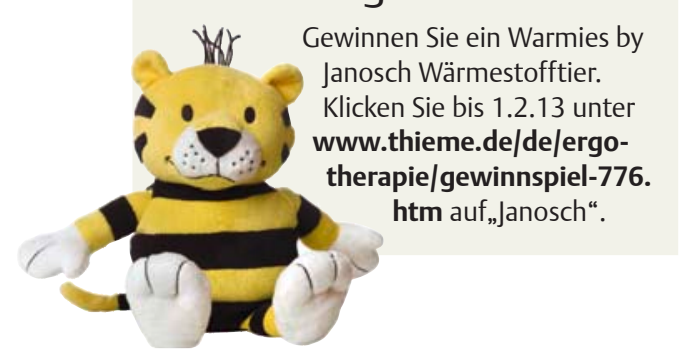

\section{ROLLZ MOTION}

\section{Rollator und Rollstuhl in einem}

Mehr Lebensqualität durch Flexibilität - das verspricht das holländische Unternehmen Rollz und entwickelte einen faltbaren Rollator, der sich bei Bedarf in einen Rollstuhl verwandeln lässt. Mithilfe dieses Produkts sollen Menschen mit Gehbeeinträchtigung die Angst vor Distanzen verlieren und mobil bleiben. Wer eine Pause braucht, macht aus dem Rollator im Handumdrehen einen Rollstuhl. Zusammengeklappt passt das Gerät in den Kofferraum beziehungsweise aufrecht hinter den Beifahrersitz. Der Rollator wiegt 10,6 kg, das Rollstuhlpaket 3,7 kg. Das Gesamtgewicht beträgt also 14,3 kg.

Ein Blickfang ist das Design: Durch das farbenfrohe Gestell wirkt der 2-in-1-Rollator fröhlich und modern. Er kostet 759 Euro und ist derzeit in vier Farben erhältlich. Man kann ihn über die Homepage der Firma sowie in ausgewählten Sanitätshäusern beziehen. Nach Angaben von Rollz Deutschland

$\rightarrow$ www.rollz.com
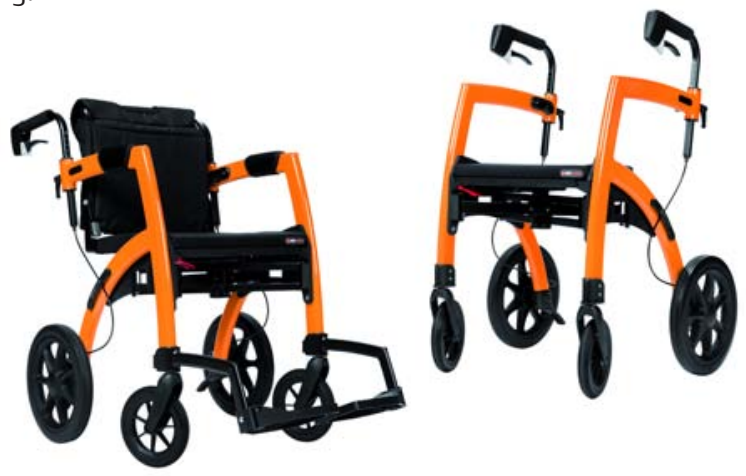

\section{SOOFT MEALS}

\section{Passiert, appetitlich und einfach zuzubereiten}

Wer auf passierte Kost angewiesen ist, freut sich, wenn das Essen appetitlich aussieht. Die Sooft Meals der Firma Resama sind wie alle passierten Speisen frei von Fleischfasern, Fruchtstücken oder Ähnlichem. Außerdem bleibt das Essen nach dem Erhitzen in der Mikrowelle oder im Backofen schnittfest und behält seine Form. Klienten können also weiterhin Messer und Gabel benutzen - ein wichtiger Faktor, um die Lebensqualität zu erhalten. Zudem sind die Speisen fein gewürzt und schonend zubereitet, sodass ihr typischer Geschmack erhalten bleibt. Die Produktpalette reicht vom Frühstück über Mittagsmenüs bis

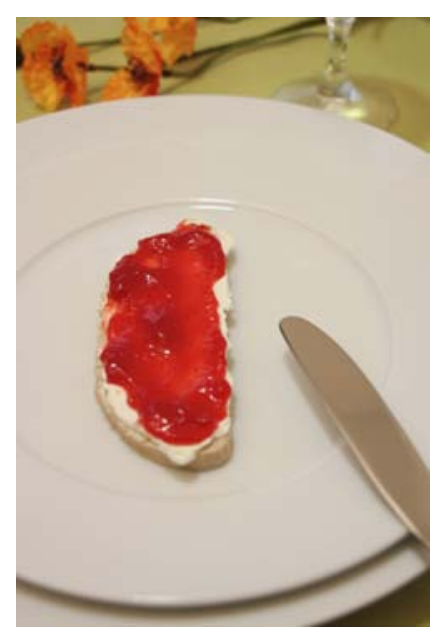
hin zum Abendessen. Highlights sind zum Beispiel das passierte Mischbrot und das laktosefreie Roggenvollkornbrot.

Die Firma bietet ihre Produkte sowohl für Großkunden als auch für Endverbraucher über ihren Online-Handel an. Wer die Produkte einmal ausprobieren möchte, könnte zum Beispiel einen Musterkarton für 25,95 Euro bestellen. Darin enthalten sind je ein Menü Fisch, ein Menü Rindergulasch sowie eine Frühstücksbox. Nach Angaben von Resama 